\title{
RIO DE JANEIRO, CAPITAL DAS ARTES
}

\section{RESUMO}

O texto analisa limites e intercâmbios entre as ditas artes plásticas e/ou visuais: desenho, pintura, escultura, arquitetura. São revistos ideais e práticas que procuraram articulações estimulantes entre as artes na modernidade, focando em experiências no Brasil, desde o início do século XX até a contemporaneidade.

PALAVRAS-ChAVE: Arte urbana; Arte pública; Arte moderna; Arquitetura moderna; Arte no Brasil.

\section{ABSTRACT}

The paper examines the limits and exchanges between the plastic and/or visual arts: drawing, painting, sculpture, and architecture. The text reviews ideals and practices that sought to stimulate linkages between the arts in modernity, with a focus on experiences in Brazil from the early twentieth century to the present.

KEYWORDS: Urban art; Public art; Modern art; Modern architecture; Art in Brazil. 
É fácil pensar os diálogos entre as ditas artes plásticas, os sentidos criados pelas complementações de pinturas, relevos e esculturas a edifícios, e de monumentos a cidades. Refletir sobre as relações tão complexas entre arquitetura e pintura, arquitetura e escultura, com suas espacialidades ora complementares, ora em oposição. Ou ainda a ideia de arquitetura como escultura habitável. Bem como o desenho de arquitetura como parte do fazer arquitetônico que adquire importância particular, ou seja, autonomia como meio expressivo. Contudo, mais do que as implicações decorrentes dos processos gerados pela condição da arquitetura como mãe das artes, é mais produtivo ver como essa condição foi revista nos tempos modernos.

Na modernidade, livres da obrigação de afirmar os poderes instituídos, especialmente os políticos, religiosos e econômicos, as artes precisaram redimensionar sua atuação pública. Tentaram conquistar uma autonomia coordenada às demais práticas humanas de reflexão e ação, especialmente entre si, das quais emergem tentativas de diálogos renovados entre as ditas artes plásticas. O museu e o espaço urbano apareceram, então, como lugares promissores onde a arte participaria da construção da cidadania: tanto da educação cívica quanto da formação estética dos cidadãos.

Desde as primeiras ações do modernismo no Brasil, ensaiou-se um novo diálogo entre as artes. A difusão da arte em edifícios e espaços urbanos é um tópico que se apresenta de modo especial. Tanto a Casa Modernista de São Paulo, quanto a do Rio de Janeiro, teve sua inauguração promovida por Gregori Warchavchik, seu autor, contando também com obras de pintura, escultura e tapeçaria feitas por artistas filiados à renovação do modernismo. A ideia era sinalizar ao público novos modos de fazer e viver a arte. Em texto seu de 1934, "Razões da nova arquitetura", Lúcio Costa explicita sua crença: "arquitetura, escultura, pintura, formam um só corpo coeso, um organismo vivo de impossível desagregação". ${ }^{1}$ Foi, contudo, a partir do projeto do edifício-sede do Ministério de Educação e Saúde, em 1936, com o incentivo de Le Corbusier, que o ideal de conjunção de urbanismo, arquitetura, escultura e pintura tornou-se quase uma obrigatoriedade.

Nessa obra, o diálogo entre as artes é desigual. Não se compreendeu a importância das dimensões previstas por Jacques Lipchitz para a escultura por ele concebida para o edifício. Os painéis de Cândido Portinari para o gabinete do Ministro participam desse diálogo plástica, política e socialmente mais retrógrado. Já seus painéis de azulejo respondem bem à espacialização do pavimento térreo, a qual é feita por meio da contraposição de espaços livre e elementos transparentes (superfícies de vidro), translúcidos (painéis de azulejo) e opacos (colunas, volumes e planos revestidos em granito). Valendo-se da diferenciação proposta por Collin Rowe, pode-se defender que a translucidez do painel de azulejos não é literal, mas fenomenológica. Ela não é sugerida pela contradição entre realidade e ilusão, como nos painéis de azulejos presentes em igrejas construídas no Brasil no século XVIII, nas quais ao mesmo tempo

\footnotetext{
${ }^{1}$ COSTA, Lucio. "Razões da nova arquitetura". In: COSTA, Lucio. Registro de uma vivência. São Paulo: Empresa das Artes, 1995, p. 109.
} 
confirma e nega a arquitetura, pois o painel era uma película através da qual, sem perder a noção de sua existência, se via uma imagem, configurando-se como uma janela turva. No caso do edifício do Ministério, o caráter translúcido advém da evidência do plano e de sua projeção no espaço, por meio da percepção imediata da fisicalidade do suporte e de sua representação imagética - uma superfície flutuante. As paredes não são visualmente sólidas (opacas) nem etéreas (transparentes); são fluidas (translúcidas). E essa translucidez não é conseguida apenas com as referências iconográficas do mar ou com a leveza das formas biomórficas usadas nas composições, mas com a suspensão do plano por meio de sua explicitação. Primeiro, com a superposição a $45^{\circ}$ de uma malha gráfica ortogonal sobre o reticulado modular formado pela aplicação do material - representação que afirma a estruturação planar, mas, repondo-a deslocada, minimiza seu peso físico e põe em suspenso a força gravitacional. Depois, pela interpenetração de diversos planos com diferentes tons de azul, segundo a lógica da espacialização pós-cubista, que afirma a planura do painel, não estabelecendo figuras sobre um fundo, e faz os planos flutuarem, projetando-os no espaço. Dinâmica de curvas e retas que perpassa painel de azulejos, edifício e jardins.

Independentemente desses erros e acertos, o diálogo entre as artes foi transformado no sexto ponto da arquitetura moderna, além dos demais propostos por Le Corbusier. Sexto ponto que foi difundido à exaustão: público ou privado, palácio ou casa, cada edifício modernista devia ter, senão todos, ao menos uma escultura, um painel cerâmico ou uma pintura mural.

A questão da cidade como síntese das artes culminou em Brasília, onde, em 1959, foi realizado o Congresso da Associação Internacional de Críticos de Arte - AICA, com o tema "A cidade nova e a síntese das artes". Um problema mal posto segundo Lucio Costa: "Seria pois integração, mais que síntese"." Como disse em outra ocasião: "O alegado divórcio das artes é tão artificioso quanto a sua fusão. A integração delas (...) é que talvez corresponda melhor à sua natureza a um tempo diferenciada e afim". ${ }^{3}$ Embora seja importante apontar que defender a ideia de integração contra a de síntese das artes revela, talvez, uma resistência em dar adeus a modalidades históricas de arte: pintura, escultura, arquitetura. Além do risco de a integração das artes retornar à concepção da arquitetura como mãe das artes e, portanto, a uma condição submissa. Algo compreensível no contexto brasileiro, em função dos compromissos do modernismo com o sistema arquitetônico de Le Corbusier e, por meio deste, com a tradição acadêmica e o classicismo, ou vice-versa.

Situando-se nesse debate em "À espera da hora plástica", Mário Pedrosa é bem enfático: "Não se pode considerar a síntese das artes como uma colaboração eventual entre arquitetos, escultores e pintores. Esta formulação só tem sentido se a estendermos a um plano social e cultural de ordem geral, se bem que qualitativo". No mesmo texto, ele refuta a interpretação de Brasília como exemplo do tema do congresso nela sediado em 1959: "Não se tratava, em momento algum, de apresentar Brasília como realização da síntese das

\footnotetext{
${ }^{2}$ COSTA, Lucio. "A arte e a educação". Arquitetura, Rio de Janeiro, IAB, n. 48, jun./1966, p. 25, 27.

${ }^{3}$ COSTA, Lucio. "Desencontro". In: COSTA, Lucio. Registro de uma vivência. Op. cit., p. 202.
} 
artes. Seria em verdade ridículo tentá-lo, porquanto Brasília, em si mesma, é apenas um pálido começo de cidade". E resume sua visão do problema:

Mas em que consiste a aspiração à síntese ou à integração? Em dar novamente às artes um papel social-cultural de primeiro plano nessa tarefa de reconstrução regional e internacional pela qual o mundo está passando ou tem de passar... se não for destruído pelos teleguiados. ${ }^{4}$

Ou seja, tratava-se e ainda se trata de promover uma integração sociocultural e não a simples adição de pinturas e esculturas a edifícios, praças e ruas, como muitas vezes se manifesta nas ideias de síntese ou integração das artes, assim como de arte pública ou urbana, como se atualizou e renomeou recentemente essa problemática. Pinturas em fachadas e esculturas em praças são situações por si só insuficientes para caracterizar a experiência pública da arte, pois tanto os espaços coletivos são muitas vezes segregativos, quanto a ocupação das ruas significa pouco diante das barreiras criadas historicamente entre a arte e as massas. A questão da arte pública implica o estatuto de pintura, escultura, arquitetura e urbanismo como artes, e as artes como elementos constitutivos de uma urbanidade democrática capaz de representar e fazer interagir harmonicamente os diferentes segmentos sociais.

A experiência de Brasília é, com raras exceções, apenas a reincidência das idiossincrasias do modernismo brasileiro: a incompreensão das efetivas transformações da arte moderna (conceituais, plásticas, sociais), a subserviência aos projetos de construção da identidade nacional e de afirmação do poder do Estado, a marginalização de grandes segmentos sociais. A despeito das muitas tentativas, poucos foram os momentos consequentes de integração sociocultural, os embates onde as obras propõem desafios entre si e ao público.

Contemporâneo de Brasília, o Neoconcretismo e sua espacialização não memorialista, nem projetiva, partiu do plano pictórico e da volumetria escultural para chegar a experimentos de escala e vocação públicas que foram desenvolvidos com timidez, apenas posteriormente ou nunca efetivados. Apesar do que foi feito recentemente, com a presença de obras de Franz Weissmann e Amílcar de Castro em espaços urbanos, suas esculturas não foram exploradas até agora em sua total potencialidade de diálogo com a cidade. As arquiteturas de Lygia Clark jamais habitaram o chão da praça. As praças de Hélio Oiticica ainda estão por conquistar o território da cidade.

A construção recente, mais de duas décadas depois do falecimento do artista, de duas propostas de Magic Square de Hélio Oiticica (uma no Museu do Açude, no Rio de Janeiro, e a outra em residência particular, em Itaipava) é menos a consecução de uma das séries mais instigantes da arte no Brasil, e

\footnotetext{
4 PEDROSA, Mário. "À espera da hora plástica". Revista GAM, Rio de Janeiro, n. 4, 1967 (Republicado em PEDROSA, Mário. Acadêmicos e modernos. Textos escolhidos III. São Paulo: Edusp, 1998, p. 423-427).
} 
mais um sinal da forte institucionalização em curso no circuito de arte brasileiro. $^{5}$

Foquemos no Penetrável Magic Square no 5 - De Luxe, de Hélio Oiticica, a "primeira obra do artista exposta em caráter permanente em espaço público". ${ }^{6}$ Em um ataque às convenções museológicas tradicionais, Hélio Oiticica escreveu que "Museu é o mundo; é a experiência cotidiana: os grandes pavilhões para mostras industriais são os que ainda servem para tais manifestações; para obras que necessitem de abrigo, porque as que disso não necessitarem devem mesmo ficar nos parques, terrenos baldios da cidade (...) a chamada estética dos jardins é uma praga que deveria acabar (...) os parques são bem mais belos quando abandonados porque são mais vitais...". " Se o Espaço de Instalações Permanentes procura evitar tanto a estética dos jardins quanto a ideia do jardim de esculturas tão difundida contemporaneamente, não chega a alcançar plenamente nem as suas intenções nem as do artista. No esquema do Penetrável, Hélio Oiticica escreveu: "nesta MAGIC SQ. o chão é todo de terrinha e mato como num terreno baldio: deixar o mato crescer em diferentes alturas nos diversos pontos". ${ }^{8}$ Apesar de o mato estar crescendo em diversos pontos na instalação e desta já evidenciar o desgaste da intempérie em meio à floresta tropical, remetendo à imagem do parque abandonado, inexiste qualquer clima de terreno baldio. Configura-se, assim, uma série de contradições. O trabalho de Hélio Oiticica aparece ainda mais puro, distante dos ruídos e sujeiras urbanas, em meio à luminosidade natural da floresta, em certo sentido tão neutra, embora simétrica, quanto a brancura e o negrume intensamente iluminados, nos tipos de expografia dominantes atualmente: 0 cubo branco e a caixa preta, respectivamente. Longe das ruas, dentro do museu, a praça ganhou uma moldura - a floresta, a qual foi transformada em dispositivo museográfico que afasta a obra do efetivo confronto público que orientou a sua criação. Enquadrada pela floresta-museu, instância de dupla neutralização do Programa Ambiental do artista, a Magic Square deixa de ser praça e perde um tanto de sua mágica. "Engolida" pela instituição, a obra tem diminuídas a sua força experimental e sua condição pública.

Fato não surpreendente, pois, a partir da década de 1960, com a transformação dos sonhos artísticos e socioculturais em pesadelos, o processo de deterioração das cidades explicitou as injustiças da sociedade brasileira. Experimentações artísticas antimonumentais foram impedidas de se concretizarem ou destruídas. Dois exemplos: de Franz Weissmann, o Monumento à Liberdade de Expressão do Pensamento, instalado no Rio de Janeiro em 1954, que sobreviveu por apenas oito anos, tendo sido aniquilado para abertura de uma avenida; de Flavio de Carvalho, o Monumento a Garcia

\footnotetext{
${ }^{5}$ Ver FIgUeIREDO, Luciano (Org.). Hélio Oiticica. A pintura depois do quadro. Rio de Janeiro: Silvia Roesler Edições de Arte, 2008, p. 248-254.

${ }^{6}$ ALENCAR, Vera de. [s. t.] In: DOCTORS, Marcio. Espaço de instalações permanentes do Museu do Açude. Rio de Janeiro: Museu do Açude, 2000, p. 5.

7 OITICICA FILHO, Cesar. "HO Supercromático". In: DOCTORS, Marcio. A Forma na floresta: Espaço de instalações permanentes. Rio de Janeiro: Museu do Açude, 1999, p. 7.

${ }^{8}$ OITICICA, Hélio. "Esquema e apontamentos do Magic Square no 5 - De Luxe". In: DOCTORS, Marcio. Forma na floresta: Espaço de instalações permanentes. Op. cit., p. 13.
} 
Lorca, instalado em São Paulo em 1968, que foi destruído por vândalos do Comando de Caça aos Comunistas, no ano seguinte, e restaurado em 1970.

Em paralelo, continuaram sendo erguidos monumentos miméticos e de celebração das causas mais díspares, alguns por movimentos sociais, outros para e até contra eles. Muitas obras celebram efemérides herméticas e particulares, as quais, mais do que construir e afirmar identidades, participam da segmentação social do espaço urbano, um modo de espacialização problemático, excessivo e desordenado; afinal, nos resíduos espaciais do urbanismo modernista, há sempre uma sobra de espaço onde por uma escultura ou um mural. ${ }^{9}$ No caso das estátuas, há uma mobilidade inusitada devido a substituições, transferências e realocações: uma "dança" das peças pela cidade que é contraditória com o princípio do monumento de inscrever um significado simbólico em um espaço específico, e contraditória também com o sono eterno a que se entregam as figuras quando são encarnadas em bronze ou pedra. O que gera reações nos cidadãos que vão desde a rejeição e o humor até a agressão, física ou verbal: zombar, apelidar, fantasiar, pichar, roubar e destruir as obras são táticas de intervenção no espaço coletivo, um modo de apropriação, muitas vezes transgressor, de uma sociedade civil talvez pouco civilizada, mas, também, menos passiva no trato do seu ambiente. A esse respeito vale lembrar as polêmicas suscitadas em torno da presença de duas esculturas abstratas que, apesar da apropriação afetiva, não deixaram de gerar protestos: a "Estrela" de Tomie Ohtake, instalada primeiro na lagoa Rodrigo de Freitas e depois transferida para o Riocentro, e a "Baleia" de Angelo Venosa, instalada primeiro na Praça Mauá e depois implantada na praia do Leme.

Com a persistência do ideal modernista de integração das artes, pintores e escultores continuaram sendo chamados para participar da criação de novos espaços. Também foram convocados a posteriori para amenizar os equívocos da ocupação urbana desordenada. Visando a disfarçar volumetrias absurdas, foram criados murais nas empenas dos edifícios como os de Alfredo Volpi, Tomie Ohtake e Cláudio Tozzi em São Paulo. Para oferecer um duplo refúgio - o paisagismo e a arte - , difundiu-se a ideia dos jardins de esculturas como 0 Parque da Catacumba, no Rio de Janeiro. Esses esforços de humanização da metrópole acreditavam na obra de arte como oásis capaz de compensar o caos urbano. Aliada à potência do excepcional, a ideia da arte como instante de prazer também animou algumas realizações temporárias como o projeto Artdoor, carioca e paulistano, e o Parque de Esculturas Efêmeras, em Fortaleza, ambos da década de 1980.

A recorrência da questão parece boa, mas não é, pois produz o justo oposto de suas intenções: somas de mais, resultados de menos. A insistência em levar a arte às ruas corre o risco de banalizar o extraordinário, seja com a proliferação ad nauseum de obras permanentes, seja com a rotinização do eventual. A superposição de diálogos entre musas quase cegas, surdas e mudas

\footnotetext{
${ }^{9}$ A esse respeito, ver, por exemplo: KNAUSS, Paulo (Org.). Cidade vaidosa. Imagens urbanas do Rio de Janeiro. Rio de Janeiro: Sette Letras, 1999.
} 
propaga na urbe fragmentada uma massa de discursos paradoxal: ao mesmo tempo ensurdecedora e inaudível.

Pode-se perguntar: na experiência de mal estar na periferia, onde as artes parecem sempre inadequadas frente às premências sociais, há algum sentido na prática de fixar pinturas nas empenas cegas e de pousar esculturas no cimento frio das praças? Porém, experiências recentes reiteram a crença no diálogo entre as artes na cidade.

No campo da arquitetura e do urbanismo, frente à necessidade de reestruturação dos espaços urbanos, as demais artes foram chamadas a participar da construção de referências físicas e simbólicas que balizem o espaço coletivo. A revisão do paradigma técnico-científico modernista deu-se, em grande parte, com o retorno aos braços da história e da arte, recuperando princípios e formas antes postos em suspenso. A leitura contemporânea de marcos urbanos tradicionais é uma tendência dominante, por exemplo, nas realizações do projeto carioca Rio-Cidade, da década de 1990, pontuadas por pirâmides, obeliscos, arcos, chafarizes e estátuas. Contudo, por vezes, o que se encontra é um funcionalismo mal disfarçado em vestes nostálgicas e antiquadas, o encanto ingênuo por centralidades, eixos e simetrias, o uso meramente decorativo ou pretensamente memorialístico de obras de arte, como se fosse fácil estabilizar percepções e constituir identidades em tempos de esquizofrenia e amnésia. Em Ipanema, Paulo Casé superpôs um arco e um obelisco para marcar a entrada do bairro, pontuando um lugar presente apenas na memória dos antigos moradores do bairro e da cidade. No Catete, o início da intervenção é marcado por uma estátua de José de Alencar no centro de uma ilha de tráfego, nomeada como praça, onde o escritor parece perdido, situado em meio às diferentes direções das vias e circundado por postes em ziguezague que anulam a centralidade que se pretendia afirmar. Em Vila Isabel, o grupo Archi 5 sublinha a composição urbana com uma encenação escultórica e elementos arquitetônicos em torno da figura de Noel Rosa. No conjunto, somam-se três versões do músico - estátua, medalhão e busto -, mais as calçadas com suas partituras, e, arrematando a composição, um obelisco no centro da praça. Uma reincidência estranha para o músico notório por sua frágil compleição física em vida; uma homenagem curiosa já que uma das esculturas permanece um tanto escondida no meio do canteiro da praça e outra na calçada entre as duas pistas da avenida.

No redimensionamento contemporâneo das práticas pictóricas e esculturais, a arte radicaliza seu sentido negativo e dúbio frente ao cerco institucional - o que complica a articulação dessa negatividade com positividade intrínseca e incontornável da arquitetura. Como disse Theo van Doesburg: "Arquitetura junta, conecta - pintura separa, liberta". ${ }^{10}$ Sem nostalgias de unidades e conscientes dos limites atuais da atividade criativa, os artistas tentam propiciar experiências capazes de intervir, tensionar, desvirtuar, desestabilizar e subverter as situações pré-existentes. Em intervenções como as desenvolvidas no projeto Arte/Cidade, de São Paulo, ou as intervenções do projeto de Esculturas Urbanas, no Rio de Janeiro, a arte ocupa, expõe e enfrenta as cicatrizes da cidade. Se é fato que, assim como os arquitetos,

${ }^{10}$ Apud BOIS, Yve-Alain. Painting as model. Cambridge: The MIT Press, 1990, p. 113. 
alguns artistas como José Resende e Waltércio Caldas reportam-se à tradição dos marcos urbanos, as intenções e os princípios de interpretação são completamente opostos. As experiências desses escultores pautam-se por uma negatividade poética e irônica estranha ao ideal funcionalista ainda entranhado na prática arquitetônica no Brasil.

José Resende, que tem esculturas na Praça da Sé e no campus da USP, em São Paulo, e na CSN, em Volta Redonda, já deu ao Rio de Janeiro um Passante, situado no Largo da Carioca, uma espécie de monumento ao transeunte anônimo, mas também ao perna-de-pau, que imediatamente se associou ao caráter popular do largo, com seus ambulantes e populares. Com relação à condição pública tão almejada em tantos projetos de ocupação do espaço urbano com esculturas, é preciso falar de outras experiências suas: a Vênus localizada junto à Galeria Paulo Fernandes, no Centro do Rio de Janeiro, que habitantes da cidade, além de "bolinarem", com bom-humor carioca logo batizaram de "negona"; e a peça situada no jardim de esculturas do Museu de Arte Moderna de São Paulo, no Parque do Ibirapuera, que foi transformada em verdadeiro instrumento musical urbano com a prática insólita dos frequentadores do Parque de the atirarem pedrinhas, o que seria a princípio uma agressão, mas que se revela um raro e esquisito gesto de afetividade das massas para com a arte contemporânea. Essas obras sim, são efetivamente públicas, e não apenas porque estão em espaços tidos como públicos, mas, sobretudo, porque foram apropriadas pelos transeuntes.

De Waltércio Caldas, vale destacar a obra situada no Rio de Janeiro, em uma rótula de tráfego no início da avenida Presidente Antônio Carlos (via característica da cidade Beaux-Arts) e próxima às autopistas do aterro do Flamengo (típicas do urbanismo modernista). Ele retoma o motivo obelisco, mas o põe entre aspas, pois o seu não é um, mas dois: duplicados, abstratos e inclinados, negam os eixos do entorno e subvertem a percepção dos observadores, sejam pedestres ou em veículos. Revestidos com pedras portuguesas (seguindo a pavimentação típica das calçadas cariocas) com motivo em espiral e tendendo ao infinito, desestabilizam ao fazer o chão chegar fluidamente ao céu.

Essas são, contudo, experiências excepcionais. Se, hoje, o confinamento museológico oferece um abrigo duvidoso, o céu aberto não é garantia maior de uma efetiva experiência da arte. Na modernidade, estabeleceu-se tanto a oposição entre arte e instituição - a permanente tensão com as instâncias de poder, dentro e fora do circuito de arte -, quanto a oposição entre arte e monumentalidade - a contínua problematização dos pressupostos de celebração e miméticos da tradição dos monumentos. Com o crescente declínio da condição propriamente pública de instituições e espaços urbanos na sociedade do marketing e do espetáculo, a arte poucas vezes encontra o seu lugar, seja no museu ou na praça. Nesse sentido, a arte pública é menos 0 gesto de dar 0 ar livre a pinturas e esculturas, enriquecer a arquitetura, ornamentar a urbe - enfim, chamar as artes a participar da exploração 
mercantil e espetacular do ambiente. O desafio é fazer a cidade e as artes habitarem-se crítica e criativamente.

De todo modo, o caráter ao mesmo tempo virulento e regenerativo da ação artística ainda justifica e mostra o sentido do confronto entre as artes na arena pública. Se ainda é possível fazer da cidade "nascer (a arte), como do deserto uma flor", nas palavras de Vinicius de Moraes, ${ }^{11}$ deve-se lembrar de que, no território árido da contemporaneidade, é difícil fazer brotar mais do que cactos do asfalto.

\section{Sobre o autor}

Roberto Conduru é historiador da arte, doutor em História pela Universidade Federal Fluminense (UFF).

Artigo recebido em 30 de maio de 2012.

Aprovado em 14 de janeiro de 2013.

${ }^{11}$ MORAES, Vinicius de. "Medo de amar". In: CARDOSO, Elizete. Canção do amor demais. Rio de Janeiro: Festa Discos Ltda., 1958. 